\title{
EXCEL FOR ACCOUNTING UNTUK PENYUSUNAN LAPORAN KEUANGAN PADA YAYASAN PANTI ASUHAN
}

\section{Eka Rosalina', Wiwik Andriyani ${ }^{2}$, Afridian Wirahadi ${ }^{3}$, Fera Sriyuniati4 ${ }^{4}$, dan Desi Handayani ${ }^{5}$}

\author{
1Jurusan Akuntansi, Politeknik Negeri Padang \\ Email: ekarosalina@gmail.com \\ ${ }^{2} J u r u s a n$ Akuntansi, Politeknik Negeri Padang \\ Email:wi andriani@yahoo.com \\ 3 Jurusan Akuntansi, Politeknik Negeri Padang \\ Email:afridianpadang@gmail.com \\ ${ }^{4}$ Jurusan Akuntansi, Politeknik Negeri Padang \\ Email:vra sri@yahoo.com \\ 5Jurusan Akuntansi, Politeknik Negeri Padang \\ Email:ci_e@yahoo.com
}

\begin{abstract}
Financial Statements is an accounting process that are arranged and reported objectively which can be useful for its users. Each financial statement preparation must be based on applicable financial accounting standards. One of them is the preparation of financial statements for the foundation. A foundation is a legal entity that has the aims and objectives of social, religious and humanitarian benefits. Case Study conducted at the Shine AlFalah Foundation. The procedures in preparing the financial statements of the Al Falah foundation start from with studying the transactions in the form of cash in and cash out transaction books. After that, a needs analysis is made in the preparation of financial statements using Exel For Accounting which starts from plan the Account List, making ledgers, work sheet and continuing to design the Financial Statements of the Foundation. Last is to provide assistance and training to the preparation of financial statements using Exel for Accounting.
\end{abstract}

Keywords : Financial Statements, Excel for Accounting, Yayasan.

\begin{abstract}
ABSTRAK
Laporan Keuangan merupakan sebuah proses akuntansi yang di susun dan dilaporkan secara objektif yang dapat bermanfaat bagi para pemakainya. Setiap Penyususnan laporan keuangan harus berdasarkan pada Standar akuntansi keuangan yang berlaku. Salah satu nya yaitu Penyususnan Laporan Keuangan Untuk Yayasan. Yayasan merupakan suatu badan hukum yang mempunyai maksud dan tujuan manfaat yang bersifat sosial, keagamaan dan kemanusiaan. Studi Kasus yang dilakukan pada Yayasan Shine Al-Falah. Langkah dalam Menyusun laporan keuangan yayasan al Falah dimulai dengan mempelajari transaksi berupa buku transaksi kas masuk dan kas keluar. Setelah itu, dibuat analisa kebutuhan dalam penyusunan laporan keuangan dengan menggunakan Exel For Accounting yang dimulai dari merancang Daftar Akun, pembuatan buku besar, neraca lajur dan di lanjutkan merancang laporan Keuangan Yayasan. Tahap selanjutnya adalah melaksanakan pendampingan dan pelatihan kepada dalam penyusunan Laporan keuangan dengan menggunakan Exel for Accounting.
\end{abstract}

Kata kunci : Laporan Keuangan, Excel for Accounting, Yayasan. 
ISSN 2657-1080

ISSN 1858-3687

Akuntansi dan Manajemen Vol.15, No.1, 2020

\section{Pendahuluan}

Yayasan merupakan suatu badan hukum yang mempunyai maksud dan tujuan manfaat yang bersifat sosial, keagamaan dan kemanusiaan. Yayasan didirikan dengan persyaratan formal yang di tentukan dalam undang-undang. Di Indonesia, yayasan diatur dengan Undang Undang no 28 tahun 2014 tentang Perubahan atas Undang undang no 16 tahun 2001 Tentang yayasan. Pendirian yayasan dilakukan dengan Akta Notaris dan mempunyai status berbadan hukum setelah akta pendirian memperoleh pengesahan dari Kementrian Hukum dan HAM atau pejabat yang ditunjuk. Panti Asuhan merupakan lembaga yang bergerak di bidang sosial untuk membantu anak-anak yang sudah tidak memiliki orang tua. Di dalam Kamus Besar Bahasa Indonesia (2001), panti asuhan merupakan sebuah tempat untuk merawat dan memelihara anak-anak yatim atau yatim piatu. Pengertian yatim adalah tidak memiliki seorang ayah, sedangkan yatim piatu adalah tidak memiliki seorang ayah dan ibu. Namun, tidak hanya untuk anak yatim maupun yatim piatu, panti asuhan juga terbuka untuk anak-anak selain mereka, seperti anak terlantar. Anak-anak yang kurang beruntung seperti yang dipaparkan di atas juga dapat bertempat tinggal di panti asuhan. Jumlah panti asuhan di seluruh Indonesia diperkirakan antara 5.000-8.000 yang mengasuh sampai setengah juta anak. Panti asuhan ini mengasuh anak dari latar belakang yang berbeda, seperti anak yatim, anak piatu, anak yatim piatu, anak terlantar dan anak yang tidak mampu.

Di daerah Kota Padang, banyak sekali anak anak yang kurang mampu dan jauh dari kata tidak beruntung. Anak anak yang kuarang beruntung bisa di titipkan di panti asuhan. Salah Satunya yang ada di Kota Padang adalah Yayasan panti Asuhan Al Falah.

Kendala yang dihadapi oleh Yayasan Panti Asuhan Al falah ini adalah mengenai pencatatan keuangan dan menghasilkan laporan Keuangan. Setiap donatur atau pun tamu yang datang kesana ingin mengetahui laporan keuangan yang ada, di karenakan di yayasan panti asuhan ini memiliki beberapa bidaang kegiatan, antara lain kegiatan belajar mengajar seperti SD, Mtsn, Asrama, dan unit pengelolaan Kegiatan yang menghasilkan keuangan yang nantinya bisa digunakan untuk operarional yayasan Panti Asuhan ini. Dengan masalah ini, maka Tim Pengabdian memiliki keinginan untuk membantu yayasan ini dalam melakukan pencataan keuangan yang menghasilkan laporan keuangan. Laporan yang nantinya akan di hasilkan adalah Laporan keuangan entitas Nir laba yang sesuai dengan PSAK 45.

\section{Rumusan Masalah}

Dengan kondisi dan permasalahan yang terjadi pada Yayasan Panti asuhan Al Falah, permasalahan yang dihadapi, Rendahnya pengetahuan Pengurus dalam menyusun Pelaporan keuangan Yayasan. Hal ini tergambar dari pencatatan keuangan yang dimiliki yaitu Kas masuk dan Kas Keluar Saja, sehingga perlu dilakuan pendampingan pelatihan untuk menyusun dan membuat Laporan keuangan dengan aplikasi Exel For Accounting.

\section{Solusi}


Solusi yang dihadirkan dalam menyelesaikan permasalan tersebut sehingga diharapkan Yayasan panti asuhan ini adalah dapat menyusun pelaporan keuangan. dengan memberikan solusi kegiatan yang dimaksud antara lain : Bimbingan Tekniks Teknik menyusun laporan Posisi Keuangan Nir Laba, Aktivitas, Arus kas, dan catatan atas laporan keuanga dalam aplikasi Exel For accounting. Bimbingan Tekniks Teknik menyusun Catatan Atas laporan keuangan.

\section{Penyusunan Exel For Accounting}

Penyusunan untuk yayasan dapat dirinci sebagai berikut: Pembuatan Daftar Akun, Pencatatan transaksi kas di tangan dan kas dibank, Pencatatan transaksi dijurnal umum, Pembuatan Buku Besar, Pembuatan Neraca Lajur, Pembuatan Laporan Keuangan Entitas Nir laba Yayasan.

\begin{tabular}{|c|c|c|c|c|c|c|}
\hline 1 & \multicolumn{5}{|c|}{ YAYASAN SHINEAL-FALAH } & \\
\hline 2 & \multicolumn{5}{|c|}{ DAFTAR PERKIRAAN } & \\
\hline 3 & & \multirow{3}{*}{ NAMA PERKIRAAN } & & & & \\
\hline 4 & No. & & \multicolumn{3}{|c|}{ PERKIRAAN } & \\
\hline 5 & PERKIRAAN & & $\mathbf{D} / \mathbf{K}$ & LPK/LA & Jenis & \\
\hline 6 & $1-000$ & Aset & D & LPK & & \\
\hline 7 & $1-100$ & Aset Lancar & D & LPK & & \\
\hline 8 & $1-110$ & Kas di tangan & $\mathrm{D}$ & LPK & & \\
\hline 9 & $1-111$ & Kas Bank BNI & $\mathrm{D}$ & LPK & & \\
\hline 10 & $1-112$ & Kas Bank BRI Yayas an & $\mathrm{D}$ & LPK & & \\
\hline 11 & $1-113$ & Kas Bank Nagari & $\mathrm{D}$ & LPK & & \\
\hline 12 & $1-114$ & Kas Bank BCA & D & LPK & & \\
\hline 13 & $1-115$ & Kas Bank BRI - Pondok & $\mathrm{D}$ & LPK & & \\
\hline 14 & $1-116$ & Kas Bank BRI - Ziswaf & $\mathrm{D}$ & LPK & & \\
\hline 15 & $1-117$ & Kas Bank Mandiri - Ziswaf & $\mathrm{D}$ & LPK & & \\
\hline 16 & $1-118$ & Kas di Koperasi & $\mathrm{D}$ & LPK & & \\
\hline 17 & $1-120$ & Aset Lancar Tidak Terikat & $\mathrm{D}$ & LPK & & \\
\hline 18 & $1-121$ & Piutang Karyawan & $\mathrm{D}$ & LPK & & \\
\hline 19 & $1-122$ & Piutang Koperasi & $\mathrm{D}$ & LPK & & \\
\hline 20 & $1-130$ & Bahan habis Pakai & $\mathrm{D}$ & LPK & & \\
\hline 21 & $1-140$ & Sewa di bayar dimuka & $\mathrm{D}$ & LPK & & \\
\hline 22 & $1-150$ & Persediaan Dapur & $\mathrm{D}$ & LPK & & \\
\hline 23 & $1-160$ & Perlengkapan & $\mathrm{D}$ & LPK & & \\
\hline 24 & $1-200$ & Aset Tidak Lancar & $\mathrm{D}$ & LPK & & \\
\hline 25 & $1-201$ & Aset Tetap Tidak Terikat & $\mathrm{D}$ & LPK & & \\
\hline 26 & $1-210$ & Kendaraan & $\mathrm{D}$ & LPK & & \\
\hline 27 & $1-220$ & Akumulasi Penyusutan Kendaraan & $\mathrm{D}$ & LPK & & \\
\hline 28 & $1-230$ & Peralatan Yayas an & $\mathrm{D}$ & LPK & & \\
\hline 29 & $1-240$ & Akumulasi Penyusutan Peralatan Yayas an & $\mathrm{D}$ & LPK & & \\
\hline 30 & $1-250$ & Fumiture & $\mathrm{D}$ & LPK & & \\
\hline
\end{tabular}

Gambar 1. Daftar Perkiraan 
ISSN 2657-1080

ISSN 1858-3687

Akuntansi dan Manajemen Vol.15, No.1, 2020

\begin{tabular}{|c|c|c|c|c|c|c|c|c|c|c|}
\hline \multicolumn{11}{|c|}{$\begin{array}{l}\text { YAYASAN SHINE AL-FALAH } \\
\text { NERACA LAJUR }\end{array}$} \\
\hline \multicolumn{11}{|c|}{ BULAN : JULY 2019} \\
\hline $\mathrm{Na}$ & \multirow{2}{*}{ Nama Perkiraan } & \multirow{2}{*}{$\begin{array}{l}\text { Perkiraan } \\
\text { D/K }\end{array}$} & \multicolumn{2}{|c|}{ Neraca Saldo } & \multirow{2}{*}{\begin{tabular}{|c|} 
Perkiraan \\
LPK/LA
\end{tabular}} & \multicolumn{2}{|c|}{ Laporan Aktivitas } & \multicolumn{3}{|c|}{ Neraca } \\
\hline Perk & & & Dehit & Kredit & & Debit & Kredit & & Debit & Kredit \\
\hline $1-000$ & Aset & D & $\mathrm{Rp}$ & $\mathrm{Rp}$ & LPK & $R p$ & $\mathrm{Rp}$ & & $R p$ & $\mathrm{Rp}$ \\
\hline $1-100$ & Aset Lancar & D & Rp & Rp & LPK & $R p$ & $\mathrm{Rp}$ & & $\mathrm{Rp}$ & $\mathrm{Rp}$ \\
\hline $1-110$ & Kas ditangan & $\mathrm{D}$ & $\begin{array}{ll}\mathrm{Rp} & 114,070,000 \\
\end{array}$ & $\mathrm{Rp}$ & LPK & $\mathrm{Rp}$ & $\mathrm{Rp}$ & & $\begin{array}{ll}R p & 114,070,000 \\
R\end{array}$ & $\mathrm{Rp}$ \\
\hline $1-111$ & Kas Bank BNI & D & $19,565,624$ & Rp & LPK & Rp & Rp & & $\begin{array}{ll}\mathrm{Rp} & 19,565,624 \\
\end{array}$ & $\mathrm{Rp}$ \\
\hline $1-112$ & Kas Bank BRI Yayas an & D & $10,432,186$ & $\mathrm{Rp}$ & LPK & $\mathrm{Rp}$ & $\mathrm{Rp}$ & & $10,432,186$ & $\mathrm{Rp}$ \\
\hline $1-113$ & Kas Bank Nagari & D & $17,237,696$ & $\mathrm{Rp}$ & LPK & $\mathrm{Rp}$ & $\mathrm{Rp}$ & & $17,237,696$ & $\mathrm{Rp}$ \\
\hline $1-114$ & Kas Bank BCA & D & $1,211,083$ & $\mathrm{Rp}$ & LPK & $\mathrm{Rp}$ & $\mathrm{Rp}$ & & $1,211,083$ & $\mathrm{Rp}$ \\
\hline $1-115$ & Kas Bank BRI - Pondok & D & $4,132,034$ & $\mathrm{Rp}$ & LPK & $\mathrm{Rp}$ & $\mathrm{Rp}$ & & $4,132,034$ & $\mathrm{Rp}$ \\
\hline $1-116$ & Kas Bank BRI - Ziswaf & D & $20,470,574$ & $R p$ & LPK & $R p$ & $\mathrm{Rp}$ & & $20,470,574$ & $\mathrm{Rp}$ \\
\hline $1-117$ & Kas Bank Mandin - Ziswaf & D & $7,625,548$ & Rp & LPK & Rp & $\mathrm{Rp}$ & & $7,625,548$ & $\mathrm{Rp}$ \\
\hline $1-118$ & Kas di Koperasi & D & $281,000,000$ & Rp & LPK & Rp & $\mathrm{Rp}$ & & Rp $281,000,000$ & $\mathrm{Rp}$ \\
\hline $1-120$ & Aset Lancar Tidak Terikat & D & $\mathrm{Rp}$ & $R p$ & LPK & $\mathrm{Rp}$ & $\mathrm{Rp}$ & & $\mathrm{Rp}$ & $\mathrm{Rp}$ \\
\hline $1-121$ & \begin{tabular}{|l|} 
Piutang Karyawan \\
\end{tabular} & D & $13,365,000$ & $\mathrm{Rp}$ & LPK & $\mathrm{Rp}$ & $\mathrm{Rp}$ & & $13,365,000$ & $\mathrm{Rp}$ \\
\hline $1-122$ & Piutang Koperasi & D & $2,000,000$ & $R p$ & LPK & Rp & Rp & & $2,000,000$ & $\mathrm{Rp}$ \\
\hline $1-130$ & Bahan habis Pakai & $\mathrm{D}$ & $10,000,000$ & $\mathrm{Rp}$ & LPK & $\mathrm{Rp}$ & $\mathrm{Rp}_{\mathrm{p}}$ & & $10,000,000$ & $\mathrm{Rp}$ \\
\hline $1-140$ & Sewa di bayar dimuka & $\mathrm{D}$ & $18,333,333$ & $\mathrm{Rp}$ & LPK & $\mathrm{Rp}$ & $\mathrm{Rp}$ & & $18,333,333$ & $\mathrm{Rp}$ \\
\hline $1-150$ & Persediaan Dapur & D & $98,722,500$ & $\mathrm{Rp}$ & LPK & $\mathrm{Rp}$ & $\mathrm{Rp}$ & & $98,722,500$ & $\mathrm{Rp}$ \\
\hline $1-160$ & Perlengkapan & D & $35,161,000$ & $\mathrm{Rp}$ & LPK & $\mathrm{Rp}$ & $\mathrm{Rp}$ & & $35,161,000$ & $\mathrm{Rp}$ \\
\hline $1-200$ & Aset Tidak Lancar & D & $\mathrm{Rp}$ & $\mathrm{Rp}$ & LPK & $\mathrm{Rp}$ & $\mathrm{Rp}$ & & $\mathrm{Rp}$ & $\mathrm{Rp}$ \\
\hline $1-201$ & Aset Tetap Tidak Terikat & D & $\mathrm{Rp}$ & $\mathrm{Rp}$ & LPK & $R p$ & $\mathrm{Rp}$ & & $\mathrm{Rp}$ & $\mathrm{Rp}$ \\
\hline 1210 & Kandarnan & $n$ & $12412 \mathrm{n} \mathrm{mnn}$ & $\mid \mathrm{Dn}_{n}$ & $T D E$ & $\mathrm{Rn}$ & $1 \mathrm{Bn}_{n}$ & & $124120 \mathrm{~nm}$ & $\mathrm{Rn}$ \\
\hline
\end{tabular}

Gambar 2. Neraca Lajur

YAYASAN SHINEAL-FALAH

LAPORAN AKTIVITAS

UNTUK PERIODE YANG BERAKHIR BULAN JULY 2019

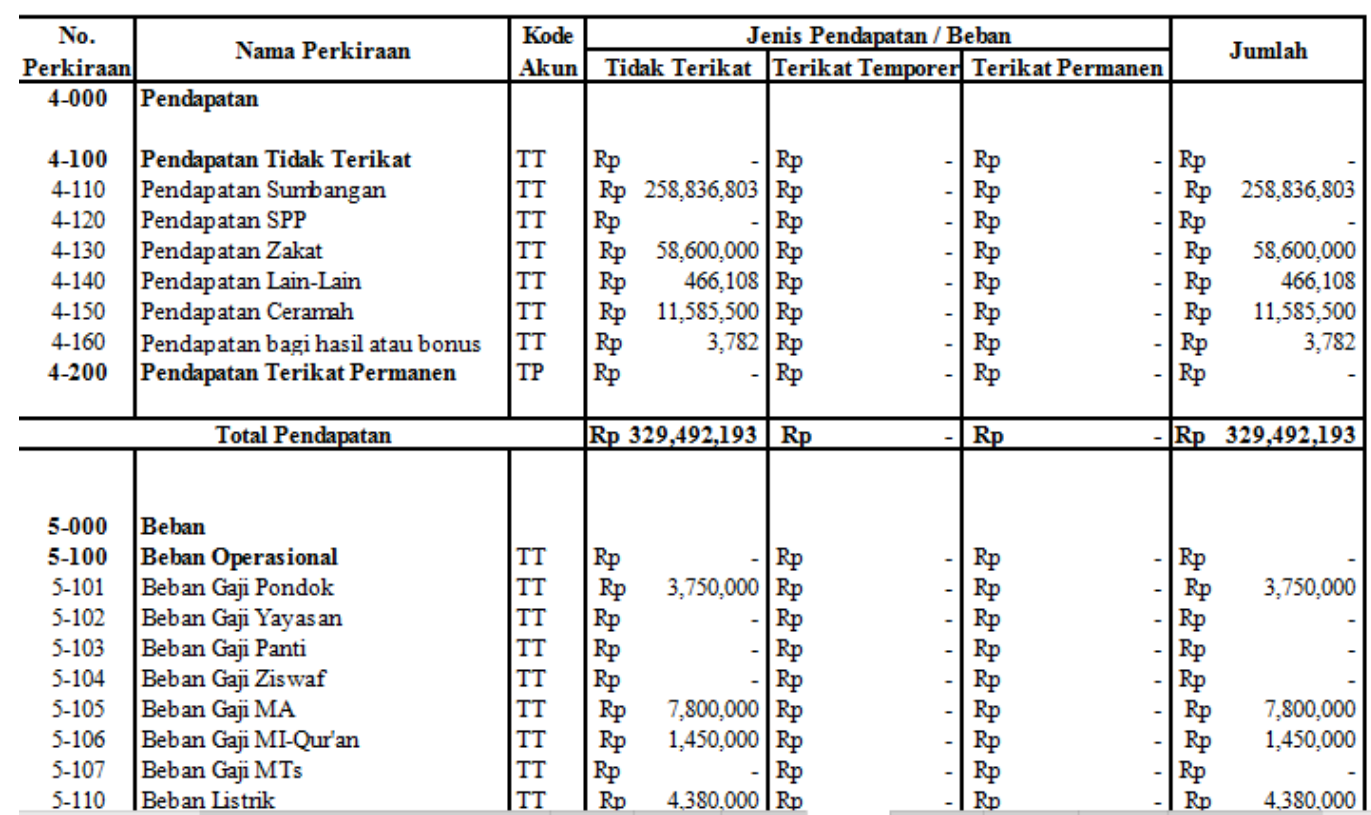

Gambar 3. Laporan Aktivitas 


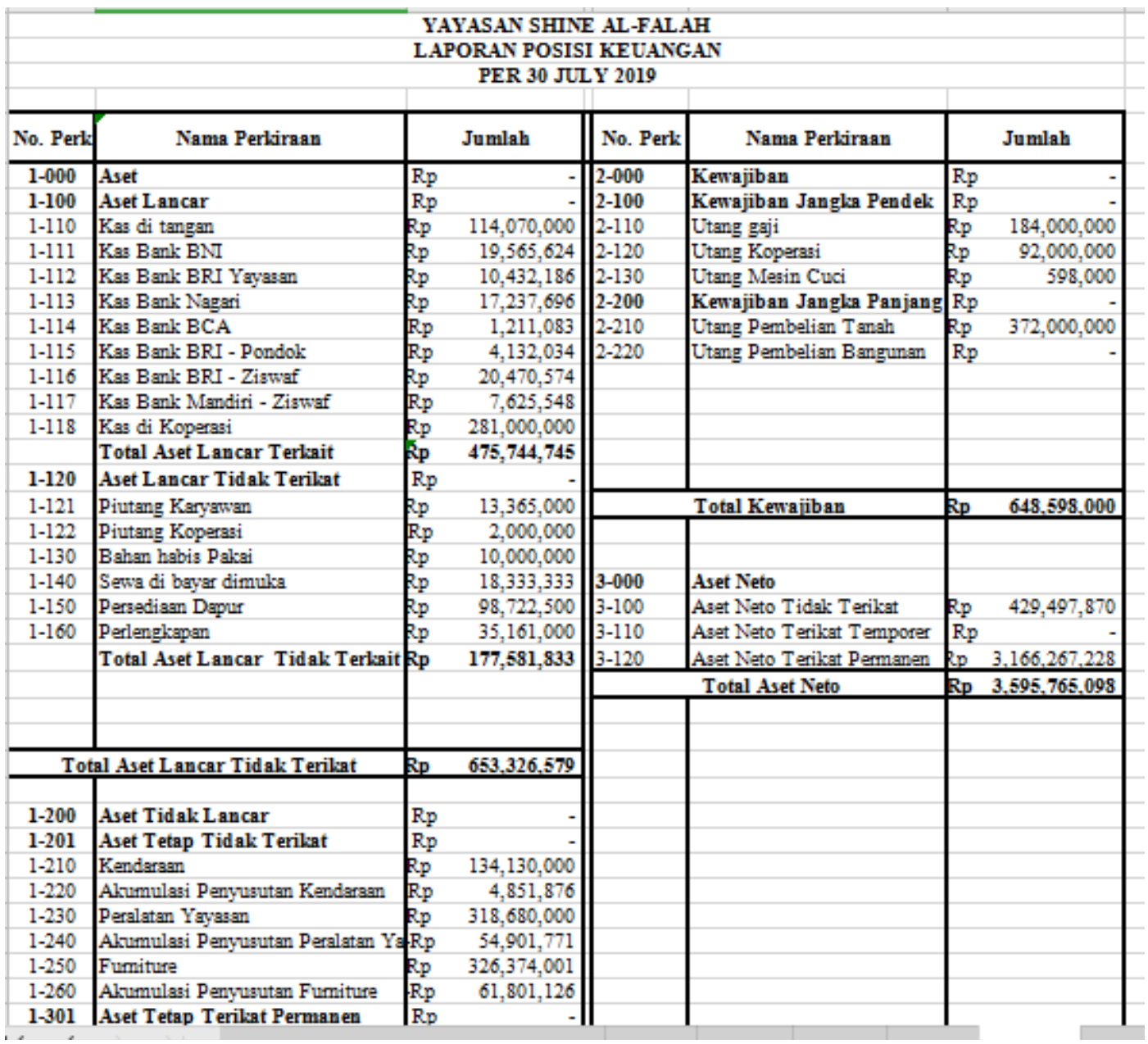

Gambar 4. Laporan Posisi Keuangan

\section{Pendampingan Penggunaan Excel for Accounting}

Setelah Excel for Accounting diselesaikan kemudian dilakukan pencatatan transaksi dengan data yang telah ada sebelumnya sehingga dapat menampilkan gambaran nyata dalam sebuah hasil dari laporan keuangan Entitas Nirlaba.

\section{Kesimpulan}

Kendala Yayasan Panti Asuhan Al falah adalah mengenai pencatatan keuangan dan menghasilkan laporan Keuangan. Setiap donatur atau pun tamu yang datang kesana ingin mengetahui laporan keuangan yang ada, di karenakan di yayasan panti asuhan ini memiliki beberapa bidang kegiatan, antara lain kegiatan belajar mengajar seperti SD, Mtsn, Asrama, dan unit pengelolaan Kegiatan yang menghasilkan keuangan yang nantinya bisa digunakan untuk operarional yayasan Panti 
ISSN 2657-1080

ISSN 1858-3687

Akuntansi dan Manajemen Vol.15, No.1, 2020

Asuhan ini. Sehingga dirancanglah Exel For Accounting Yayasan yang dapat,menghasilkan laporan keuangan yang dapat digunakan oleh Bendahara keuangan Yayasan.

\section{Referensi}

Ikatan Akuntansi Indonesia, 2009, Standar Akuntansi Keuangan, Penerbit Salemba empat, Jakarta.

Warren, S. 2012, Pengantar Akuntansi-Adaptasi Indonesia, Penerbit Salemba Empat, Jakarta.

Peraturan Pemerintah Nomor 32 Tahun 2013 tentang Standar Nasional Pendidikan

Undang undang Nomor 28 tahun 2004 tentang Perubahan atas undang undang nomor 16 tahun 2001 tentang Yayasan

Http;//www.id.m.wikipedia.org 